\title{
Unequal Limb Length, CTCAE
}

National Cancer Institute

\section{Source}

National Cancer Institute. Unequal Limb Length, CT CAE. NCI Thesaurus. Code C143894.

A disorder characterized by a discrepancy between the lengths of the lower or upper extremities. 